\title{
AVALIAÇÃO DE UM PROTOCOLO PARA MULTIPLICAÇÃO IN VITRO DA BANANEIRA (Musa sp.) CV. CAIPIRA (AAA) ${ }^{1}$
}

\author{
MARCELO FIDELES BRAGA², MARIA EUGÊNIA LISEI DE SÁ E PATRÍCIA CRYSTIE MUSTAFÁ ${ }^{4}$
}

\begin{abstract}
RESUMO - Explantes de bananeira cv. Caipiras (AAA) foram cultivados in vitro. Nas subculturas de estabelecimento e multiplicação, o meio utilizado foi MS $+5 \mathrm{mg} / 1$ de BAP e, na de enraizamento, $50 \% \mathrm{MS}$ sem BAP. Na avaliação das subculturas, a maior contaminação ocorreu no estabelecimento $(74,7 \%)$, seguindo decrescente até o enraizamento, com 5,6\%. O número de brotos por frasco diminui ao longo das subculturas, atingindo 3,7 brotos na subculturas 1 e 1,7 na subcultura 4 . O tamanho dos brotos permaneceu entre 24 e $26 \mathrm{~mm}$, nas subculturas de 1 a 3, diminuindo na subcultura 4, com $22 \mathrm{~mm}$. Como conseqüência, a classe de brotos menores $(\mathrm{x} \leq 20 \mathrm{~mm})$ predominou, variando de $56 \%$ na subcultura 1 para $65 \%$ na subcultura 4 . No enraizamento, a predominância (62\%) foi de brotos na faixa entre 30 e 60 mm, com média de 4,6 brotos por frasco. A avaliação geral do processo indicou um rendimento real de 70,9 mudas/rizoma.
\end{abstract}

Palavras-chave: Micropropagação, Banana, Cultura de Tecidos

\section{EVALUATION OF A COMMERCIAL PROTOCOL FOR IN VITRO MULTIPLICATION OF BANANA (Musa sp) CV. CAIPIRA (AAA)}

\begin{abstract}
Banana explants cv. Caipira (AAA) was cultivated in vitro. In the establishment and multiplication phases the medium used was $\mathrm{MS}+5 \mathrm{mg} / \mathrm{l} \mathrm{BAP}$ and in the rooting phase, $50 \% \mathrm{MS}$ without BAP. In the subcultures evaluations, the highest contamination rate occurred at the establishment (74,7\%), decreasing until rooting, with 5,6\%. The number of shoots per flask along the subcultures was 3,7 in the first subculture and 1,7 in the fourth. The shoots' size remained between 24 and $26 \mathrm{~mm}$ in the subcultures 1 to 3 , reducing in the subculture 4 with $22 \mathrm{~mm}$. As a consequence, the class of smaller shoots $(x \leq 20 \mathrm{~mm})$ was predominant, from $56 \%$ in the subculture 1 to $65 \%$ in the subculture 4 . During rooting, the predominance (62\%) of shoots was between 30 and $60 \mathrm{~mm}$, with 4,6 shoots per flask. The general evaluation of the process indicated an efficiency of 70,9 plantlets per rhizome.
\end{abstract}

Key words: Micropropagation, Banana, Tissue Culture

\section{INTRODUÇÃO}

A banana, Musa spp, é uma das frutas mais consumidas no mundo e na maioria dos países tropicais. No Brasil, a bananeira é cultivada de norte a sul, numa área aproximada de 521.200 ha, envolvendo desde a faixa litorânea até os planaltos interioranos, sendo $99 \%$ da produção destinada ao mercado interno (Borges et al., 1997). No estado de Minas Gerais, a cultura tem se expandido grandemente, principalmente na região Nordeste, devido aos projetos de irrigação (Cançado Júnior et al., 1999).

O grande crescimento da bananicultura, ocorrido nos últimos anos, acarretou uma forte demanda por mudas, muitas vezes de origem duvidosa (Silva et al., 1999), aumentando a incidência de pragas e doenças e, conseqüentemente, resultando em baixo rendimento dos cultivos (Pereira et al., 1999).

A micropropagação da banana consiste em isolar ápices vegetativos de filhos de matrizes vigorosas e produtivas, em condições assépticas, em meio de cultura in vitro. Em tais condições, proporciona-se uma profícua brotação de gemas axilares a partir do ápice vegetativo isolado. As principais vantagens deste método são a alta taxa de multiplicação em comparação aos métodos tradicionais e à alta qualidade fitossanitária das mudas. Além disso, a micropropagação é muito utilizada para produção de mudas básicas de novas cultivares de bananeira desenvolvidos pelos programas de melhoramento genético. Dessa forma, é possível atender com maior rapidez e eficiência às necessidades dos produtores.

O presente trabalho teve como objetivo avaliar o desempenho de um protocolo de micropropagação de bananeira, cultivar Caipira (AAA), introduzida da África Ocidental pela Embrapa Mandioca e Fruticultura, resistente a Sigatoka Amarela, a Sigatoka Negra e ao Mal-do-Panamá, uma vez que esta cultivar constitui material de grande importância para as regiões de cultivo da bananeira.

\section{MATERIAIS E MÉTODOS}

Rizomas de bananeira cultivar Caipira foram retirados de matrizes em campo, na EMBRAPA, em Cruz das Almas-BA e enviados para o Laboratório de Biotecnologia da EPAMIG, em Uberaba-MG. Após três dias de viagem, foi feita uma pré-limpeza do material, retirada de explantes e desinfestação. Para a desinfestação, foi utilizada lavagem em água e sabão, em seguida,

1 Trabalho $n^{\circ}$ 194/2000. Recebido: 04/09/2000. Aceito para publicação: 18/07/2001. Apoio Financeiro : Fundação Triângulo e Fapemig 2 Eng. ${ }^{\circ}$ Agr. ${ }^{\circ}$, MSc - Pesquisador em Fruticultura/Biotecnologia da EPAMIG/CTTP (fideles@mednet.com.br), CP351, Uberaba-MG, CEP:38.001-970

3 Bióloga, MS - Pesquisadora em Biotecnologia da EPAMIG/CTTP

4 Acadêmico de Ciências Biológicas/FEU, bolsista da EPAMIG/CTTP 
em câmara de fluxo laminar, imersão em álcool $70 \%$ por 1 min, em hipoclorito de sódio por $20 \mathrm{~min}$ e lavagem em três águas autoclavadas. Foram estabelecidos 300 explantes de bananeira cv. Caipira, com as seguintes dimensões : $0,5 \mathrm{~cm}$ de rizoma, $1 \mathrm{~cm}$ de primórdios foliares e $1 \mathrm{~cm}$ de diâmetro. Os explantes permaneceram 30 dias na fase de estabelecimento.

Nas fases de estabelecimento e multiplicação, cada recipiente conteve $50 \mathrm{ml}$ do meio de cultura constituído pela mistura de sais e vitaminas de MS (Murashige e Skoog, 1962), suplementado com $5 \mathrm{mg} / \mathrm{l}$ de benzilaminopurina (BAP), $30 \mathrm{~g} / \mathrm{l} \mathrm{de}$ sacarose e $8 \mathrm{~g} / 1$ de agar. A fase de multiplicação teve 5 subcultivos, cada um com duração média de 30 dias. No primeiro subcultivo de multiplicação, cada explante foi retirado e cortado longitudinalmente ao meio e as duas metades subcultivadas para novo meio em recipientes diferentes.

A partir do segundo subcultivo de multiplicação, ao final de cada subcultura, os tufos de brotações sadios tiveram as folhas cortadas e foram divididos longitudinalmente em partes iguais ( $2 ; 3$ ou 4 partes, conforme o tamanho do tufo) para expor seus pontos de crescimento ao meio nutritivo, sendo um recipiente novo para cada parte dividida. Ao término da subcultura 5 , os tufos foram subcultivados em meio de enraizamento.

Para iniciar a fase de enraizamento, os tufos de brotações obtidos da fase anterior foram divididos, de forma que os brotos com mais de $1 \mathrm{~cm}$ de cartucho foram individualizados, e os tufos com gemas não desenvolvidas foram divididos em partes iguais. Os procedimentos para a retirada dos tufos, divisão e subcultivo foram os mesmos da fase anterior, exceto que não se cortaram as folhas dos brotos. Todo o material foi subcultivado em recipientes com $80 \mathrm{ml}$ de meio de cultura constituído de $50 \%$ da concentração original de MS, $15 \mathrm{~g} / \mathrm{l}$ de sacarose e $8 \mathrm{~g} / \mathrm{l}$ de ágar, sem reguladores de crescimento. Cada recipiente recebeu 4 brotos (ou tufos subdivididos), e a fase de enraizamento teve a duração de 30 dias. Ao final desta subcultura, de um total de 2.446 frascos, foram amostrados 818 , que tiveram seus brotos $(\geq 10 \mathrm{~mm})$ retirados e avaliados individualmente quanto ao número e comprimento do colo da plântula até a roseta foliar. O restante dos frascos foi aberto e as plântulas, aclimatadas.

Na sala de incubação, a temperatura média foi de $25^{\circ} \mathrm{C}$, iluminação artificial com lâmpadas fluorescentes luz do dia, num total de 3.000 lux, com fotoperíodo de 16 horas.

$\mathrm{O}$ controle de qualidade envolveu basicamente procedimentos para evitar variações somaclonais e presença de pragas e doenças. Para controle de variações somaclonais, durante as subculturas, os tecidos com calos foram descartados e na aclimatação foi feito exame visual para detecção de possíveis plantas fora-do-padrão.

Durante a fase de crescimento in vitro, as contaminações verificadas eram anotadas e descartadas. Ao final de cada subcultura, os frascos foram amostrados e avaliados, por fora, sem retirada das culturas, quanto ao número de brotos maiores ou iguais a $10 \mathrm{~mm}$ e o comprimento destes brotos, da base do pseudocaule até a roseta foliar. Durante a operação de subcultivo, foi anotado o rendimento de cada frasco subcultivado, ou seja, quantos frascos da subcultura seguinte cada frasco subcultivado rendeu.

As avaliações de número e comprimento de brotos da subcultura 5 foram perdidas.

\section{RESULTADOS E DISCUSSÃO}

Pelos dados apresentados na Figura 1, pode-se verificar que o número de brotos $(\geq 10 \mathrm{~mm})$ por frasco $(\mathrm{NB})$ cai significativamente ao longo das subculturas. Isto não significa que o número de gemas esteja, também, decrescendo, uma vez que, pela Tabela 1, se observa que o rendimento de frascos se mantém em torno de 3 na fase de multiplicação. Alguns autores relatam médias de número de brotos superiores às apresentadas, embora não informem se foram incluídos na contagem os brotos abaixo de $10 \mathrm{~mm}$ de comprimento (Damasco \& Barba, 1984; Lameira et al., 1991; Domingues et al., 1995). Taxas de multiplicação aproximadas foram obtidas por diversos autores sob condições semelhantes a este trabalho, porém com diferentes genótipos (Lameira et al., 1991; Oliveira \& Silva, 1997; Oliveira et al., 1999).

No fator comprimento médio dos brotos por frasco (MME), pode ser observado, na Figura 1, que o tamanho dos brotos permanece praticamente o mesmo nas subculturas de 1 a 3 , havendo, então, queda na subcultura 4. Provavelmente, o efeito cumulativo do BAP de uma subcultura para outra tenha dificultado o alongamento dos brotos (Grattapaglia \& Machado, 1990).

A Figura 2 mostra mais claramente o comportamento do número de brotos e suas classes de tamanho ao longo das subculturas. A tendência geral é de queda, sendo que a classe de brotos menores $(x<20)$ tende a predominar cada vez mais, mostrando que, além de diminuir o número de brotos, reduz também sua capacidade de crescimento.

A taxa de multiplicação foi avaliada através do rendimento de frascos de uma subcultura para outra (Tabela 1), cujos valores se encontram próximos de 3,0 nos subcultivos de 1 a 4 . De um modo geral, a literatura tem relatado valores aproximados a esta taxa nos subcultivos 2 a 4 (Oliveira \& Silva, 1997; Oliveira et al., 1999). Com relação à menor taxa de multiplicação observada no subcultivo 5 , deve-se levar em consideração que, no estabelecimento da subcultura seguinte (enraizamento), foram colocados 4 brotos (ou tufos) para cada frasco estabelecido, ao contrário das fases anteriores, nas quais cada recipiente recebeu apenas um explante. Desta forma, o rendimento da subcultura 5 não pode ser considerado para fins de comparação de rendimento de frascos com outras subculturas.

A avaliação geral da eficiência de todo o processo in vitro (Tabela 1) indica que, se todos os explantes estabelecidos chegassem ao final de cada subcultura sem contaminação, teríamos uma taxa de rendimento total de $1.077,75$ vezes o número de rizomas que entraram no processo, ou seja, 300x1.077,75 322.727 mudas. Entretanto, o rendimento real foi de 70,9 mudas/ rizoma; iniciando-se com 300 rizomas, obtiveram-se 21.257 mudas. Por estes números, chegamos à conclusão de que o rendimento potencial seria 15,3 vezes maior que o rendimento real, mostrando que as perdas por contaminação representam um grande problema que precisa ser imediatamente controlado, sob pena de inviabilizar comercialmente a técnica. A relação entre o número de mudas produzidas e o número de explantes viáveis introduzidos foi de apenas 77 vezes (21.257/277), ao passo que Mendes et al. (1996) obtiveram 676 plantas/explante (variando de 143 a 1850) para a variedade Nanicão, após seis subcultivos, enquanto Oliveira \& Silva (1997) obtiveram uma eficiência de 190 plântulas/explante viável, após o mesmo período e utilizando a mesma variedade. 
TABELA 1. Média* dos rendimentos de frascos de uma subcultura para a subcultura seguinte.

\begin{tabular}{|c|c|c}
\hline Subcultura & Rendimento & $\begin{array}{c}\text { Intervalo de confiança } \\
\text { P(0,05) }\end{array}$ \\
\hline 0 & de frascos da subcultura seguinte & 0,0 \\
\hline 1 & 2,0 & 1,0 \\
\hline 2 & 3,5 & $*$ \\
\hline 3 & 2,4 & 0,5 \\
\hline 4 & 3,6 & 0,1 \\
\hline 5 & 3,3 & 0,2 \\
\hline Enraizamento & 0,7 & \\
\hline
\end{tabular}

*As médias não puderam ser comparadas estatisticamente já que algumas subculturas não apresentaram repetições.

** Rendimento de plântulas por frasco no final da subcultura de enraizamento.

TABELA 2. Culturas contaminadas em cada subcultura.

\begin{tabular}{|c|c|c|c|}
\hline \multirow[t]{2}{*}{ Subcultura } & \multirow{2}{*}{$\begin{array}{c}\text { Total de frascos com explantes } \\
\text { sadios, que iniciaram a subcultura }\end{array}$} & \multicolumn{2}{|c|}{ Total de frascos com culturas contam inadas } \\
\hline & & $\mathrm{n}$ & $\%$ \\
\hline 1 & 184 & 53 & 28,8 \\
\hline 2 & 393 & 48 & 12,2 \\
\hline 4 & 2.166 & 559 & 25,8 \\
\hline 5 & 5.186 & 666 & 12,8 \\
\hline Enraizamento & 2.592 & 146 & 5,6 \\
\hline Total & 12.048 & 2.292 & 19,02 \\
\hline
\end{tabular}

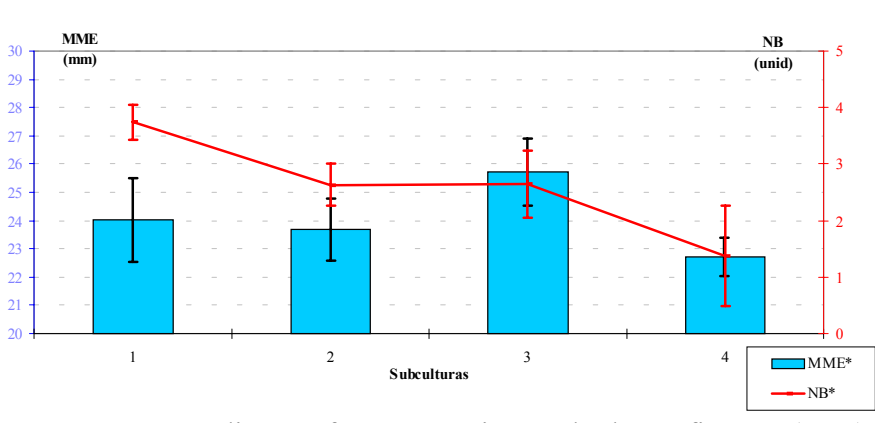

FIGURA 1. Médias por frasco, com intervalo de confiança $\mathrm{P}(0,05)$, do comprimento (MME) e número (NB) de brotos $>10 \mathrm{~mm}$, de bananeira cv. Caipira, nas subculturas de 1 a 4. Uberaba-MG, 1998.

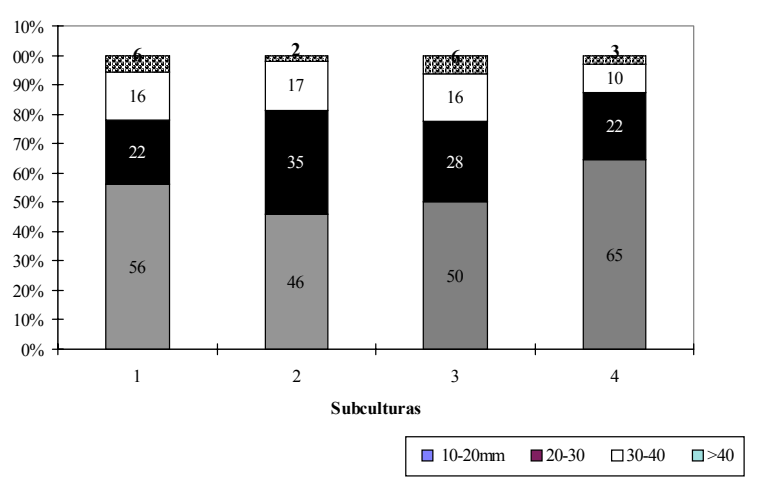

FIGURA 2. Distribuição porcentual da freqüência de brotos de bananeira cv. Caipira, conforme 4 classes de tamanho (legenda), nas subculturas de 1 a 4 . Uberaba-MG, 1998.
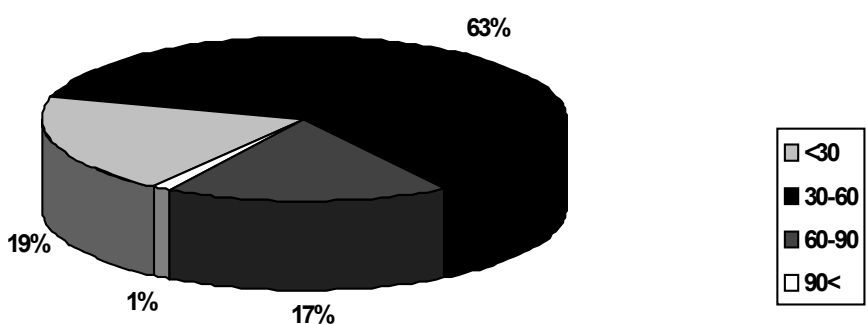

FIGURA 3. Porcentagem de brotos de bananeira cv. Caipira, por faixa de tamanho $(\mathrm{mm})$, no final da subcultura de enraizamento (amostragem por frasco). UberabaMG, 1998.

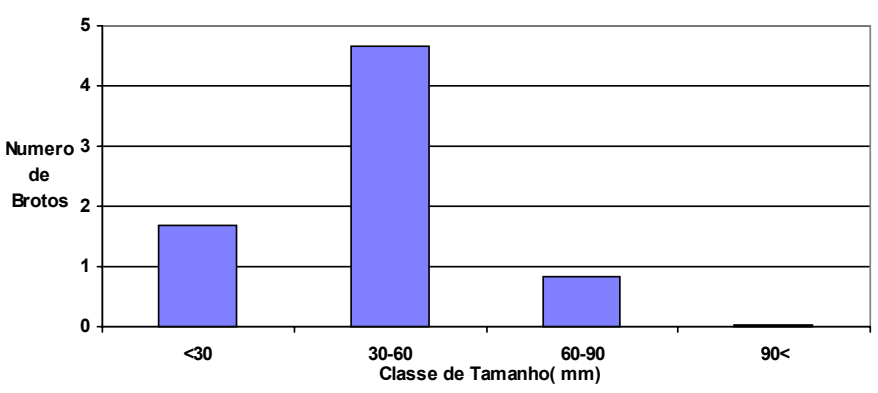

FIGURA 4. Média do numero de brotos $>10 \mathrm{~mm}$, de bananeira cv. Caipira, por frasco, por classe de tamanho. Uberaba-MG, 1998. 
Através dos dados da Tabela 2, observa-se que a maior porcentagem de contaminação ocorreu durante a fase de estabelecimento in vitro dos explantes $(74,7 \%)$, uma vez que o material foi diretamente proveniente do campo. Este nível foi decrescendo, até que, na subcultura 3, houve um acréscimo em relação a subcultura 2. Segundo Grattapaglia \& Machado (1990), este acréscimo pode ser atribuído a bactérias endógenas de crescimento lento, que representam um problema para a maioria dos laboratórios, gerando grandes perdas nas culturas em estágio avançado de multiplicação. Algumas contaminações bacterianas ocorridas foram identificadas como : Pseudomonas maltophila, Bacillus sp, Klebsiella pneumonia e Hafnia alvei.

A ocorrência de variações somaclonais é um dos fatores limitantes na expansão da utilização de plantas in vitro (Israeli et al., 1991). Na bananeira, os principais os fatores que podem induzir as variações somaclonais são a instabilidade genética dos tecidos somáticos, a presença de gemas adventícias formadas nos tecidos do rizoma (independentemente da presença de calos), a taxa de repicagens in vitro e os componentes do meio de cultura, como o uso dos reguladores de crescimento em elevadas concentrações, por exemplo, acima de 5,0 mg/L de BAP (Domingues et al., 1995). No presente trabalho, o controle da sua ocorrência foi efetuado pelo descarte de tecidos com calos, durante os subcultivos, e pela eliminação de possíveis plantas fora-do-padrão durante a aclimatação. Neste caso, não foi identificada nenhuma planta com variação somaclonal, durante a fase de aclimatação.

$\mathrm{Na}$ subcultura de enraizamento, 63\% dos brotos estiveram na faixa de tamanho entre 30 e $60 \mathrm{~mm}$ (Figura 3), obtendo-se assim 4,6 brotos por frasco, com tamanho entre 30 e $60 \mathrm{~mm}$ (Figura 4). Isto representa um resultado razoável, considerando que houve um bom rendimento de brotos por frasco, e o tamanho está adequado para a fase de aclimatação. Para classes menores, há dificuldade de sobrevivência na aclimatação, e nas classes maiores há grande desuniformidade e deformação das primeiras folhas que se enrolam ao crescer mais que a capacidade do recipiente, causando mau aspecto e dificuldade de crescimento.

A não-utilização de regulador de crescimento e a redução dos nutrientes pela metade foram eficientes para aumentar o vigor vegetativo das culturas, uma vez que os brotos obtidos durante a fase de enraizamento (tamanho médio de 45 $\mathrm{mm}$ ) apresentaram quase o dobro do tamanho dos brotos das fases de multiplicação (Figura 1). Isto já era esperado, pois, uma vez enraizados, os brotos têm maior capacidade de absorção dos nutrientes. Esta eficácia também foi comprovada por Domingues et al. (1995) e Oliveira \& Silva (1997). Inclusive, Souza \& Gonçalves (1996) sugeriram que a melhor adequação dos nutrientes favoreceria a rizogênese das plantas. Analisando diversos trabalhos, Grattapaglia \& Machado (1990) verificaram que diversas espécies, principalmente herbáceas, enraízam na presença de níveis muito reduzidos de auxina, ou, simplesmente, em meio básico sem hormônio. A concentração de sacarose reduzida pela metade também foi benéfica, pois isto facilita a passagem das plantas para o estado autotrófico durante o transplantio (Debergh, 1988).

\section{CONCLUSÃO}

1 - Os níveis de contaminações atingidos podem inviabilizar a produção comercial de mudas, num ambiente mais competitivo, sendo este o principal fator que onera o rendimento da cultura. Apenas melhorar as condições de assepsia não é suficiente, sendo necessário identificar melhor os contaminantes e formular estratégias para sua prevenção e controle, sobretudo para as contaminações com bactérias.

2 - Ainda há necessidade de estudo das concentrações de BAP. Uma dosagem constante durante todas as subculturas parece não ser o ideal, já que se suspeita de que haja um efeito cumulativo negativo do BAP ao longo das subculturas. $\mathrm{O}$ decréscimo de dosagens ou mesmo a alternância do uso do regulador, ao longo das subculturas, parece ser um ótimo caminho para aumentar o vigor das subculturas.

3 - O tamanho final das plântulas ao final do enraizamento/início da aclimatação ainda é muito desuniforme.

4 - O protocolo produziu mudas de alta qualidade genética e fitossanitária, com eficiência maior que os sistemas tradicionais de produção de mudas a campo.

\section{REFERÊNCIAS BIBLIOGRÁFICAS}

BORGES, A.L.; ALVES, E.J.; SILVA, S. de O. e; SOUZA, L. da S.; MATOS, A.P. de; FANCELLI, M.;OLIVEIRA, A.M.G.; CORDEIRO, Z.J.M.; SILVEIRA, J.R.S.; COSTA, D. da C.; MEDINA, V.M.; OLIVEIRA, S.L. de; SOUZA, J. da S.; OLIVEIRA, R.P. de; CARDOSO, C.E.L.; MATSUURA, F.C.A.U.; ALMEIDA, O. de. O cultivo da banana. Cruz das Almas : EMBRAPA-CNPMF, 1997. 109 p. (Circular Técnica, 27).

CANÇADO JUNIOR, F.L.; SOBRINHO, R.R.; MAIA, D.M. de M. e GERALDO, L.G. Aspectos econômicos da cultura da bananeira em Mians Gerais. Informe Agropecuário, Belo Horizonte, v.20, n.196, p5-9, 1999.

DAMASCO, O.P.; BARBA, R.C. In vitro culture of Saba banana [(Musa sp) cv. Saba (BBB)]. Philipine Agriculturist, Lagura,v.67, n.3, p.351-358, 1984.

DEBERG, P.C. Control of in vitro plant propagation. In : SIMPÓSIO INTERNACIONAL DE BIOTECNOLOGIA DE PLANTAS, 1., 1988, Piracicaba-SP. Anais... Piracicaba : CEBTECFEALQ-USP, 1988.

DOMINGUES, E.T.; TULMANN NETO, A.; MENDES, B.M.J. Cultura de ápices caulinares de Musa sp., var. Maçã: estabelecimento, micropropagação e enraizamento in vitro. Scientia Agrícola, Piracicaba, v.52, n.2, p.387-394, 1995.

GRATTAPAGLIA, D.; MACHADO, M.A. Micropropagação. In: TORRES, A.C. \& CALDAS, L.S. (Ed.). Técnicas e aplicações da cultura de tecidos de plantas. Brasília: EMBRAPA/CNPH, 1990. p.99-169. 
ISRAELI, Y.; REUVENI, O.; LAHAV, E. Qualitative aspects of somaclonal variations in banana propagated by in vitro techniques. Scientia Horticulturae, Amsterdam, v.48, p.71-77, 1991.

LAMEIRA, O. A.; PINTO, J.E.B.P.; PASQUAL, M. Pesquisa Agropecuária Brasileira, Brasília, v.25, n.11, p.1613-1617, 1991.

MENDES, B.M.J.; MENDES, F.J.; TULMANN NETO, A.; DEMÉTRIO, C.G.B. e PUSKE, O.R. Efficacy of banana plantlet production by micropropagation. Pesquisa Agropecuária Brasileira, Brasília, v.31, n.12, p.863-867, 1996.

MURASHIGE, T.; SKOOG, F. A revised medium from rapid growth and bioassay with tobacco tissue cultures. Phisiologia Plantarum, Copenhagem, v.15, p.473-497, 1962.

OLIVEIRA, R. P. \& SILVA, S.O. Avaliação da micropropagação comercial em bananeira. Pesquisa Agropecuária Brasileira,
Brasília, v.32, n.4, p.415-420, 1997.

OLIVEIRA, R. P.; SILVEIRA, D.G.; SILVA, K.M.; VILARINHOS, A.D . Avaliação da micropropagação de genótipos diplóides, triplóides e tetraplóides de bananeira empregando protocolo utilizado em laboratórios comerciais. Revista Brasileira de Fruticultura, Jaboticabal, v.21,n.3,p.269-273, 1999.

PEREIRA, L.V.; CORDEIRO,Z.J.M.; FIGUEIRA, A.R.; HINZ, R.H.; MATOS, A.P. Doenças da bananeira. Informe Agropecuário, Belo Horizonte, v.20, n.196, p.37-47, jan/fev.1999.

SILVA, C.R.R.; SOUTO, R;F; MENEGUCCI, J.L.P. Propagação da bananeira. Informe Agropecuário, Belo Horizonte, v.20, n.196, p.16-20,jan/fev.1999.

SOUZA, G.M.; GONÇALVES, A.N. Otimização de meio de cultura para bananeira (Musa cavendishii L.) Scientia Agrícola, Piracicaba, v. 53, n.1, p.51-59, 1996. 